\title{
Sol-Gel Transition and Critical Gel in Vulcanization Reaction
}

\section{Dario Nichetti*}

Rheonic Lab, Via Quadelle 2C, Italy

Submission: May 17, 2021; Published: June 01, 2021

*Corresponding author: Dario Nichetti, Rheonic Lab, Via Quadelle 2C, Italy

Abstract

This study highlights how the transition from uncured to cured state in rubber is characterized by the formation of a particular network structure, so-called critical gel. Critical gel is formed in the first stages of vulcanization and is independent by the macromolecular structure and crosslinking.

Keywords: Curing cycle design; Under-cure phase; Spongelike region; Blowing point; Shrinkage; Critical Gel time; Elastomer; Compound; Viscoelasticity

\section{Introduction}

Vulcanization proceeds through three different stages, as shown in Figure 1. The first stage is characterized by an induction phase in which the reactions between the curatives and macromolecules of the polymeric matrix take place. In the second, commonly known as curing stage, cross-linking reactions between the macromolecular chains take place [1-2]. The initial sol-gel transition is characterized by the formation of a "critical gel" in which each polymer chain is chemically linked to at least another one. The reaction then proceeds until the full vulcanization is reached. In the final stage, so-called over-curing reactions take place and they can cause the partial destruction of the network. This phenomenon is called reversion and, in this case, a partial loss of product performance generally occurs [3].

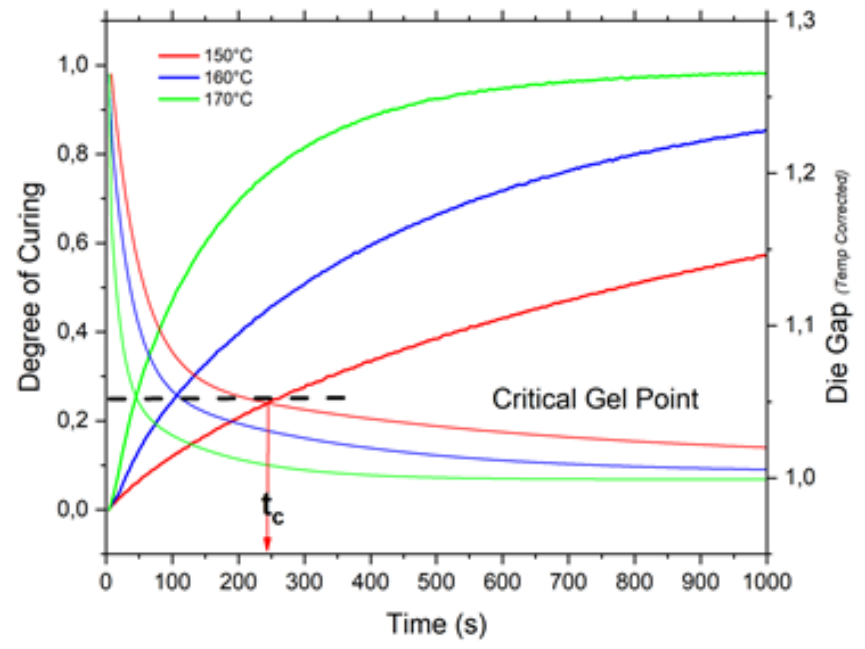

Figure 1: Elastic modulus (measured at $1 \mathrm{~Hz}, 1 \%$ strain) behavior during curing of the $\mathrm{C} 1$ compound at various temperatures. Critical gel time is also shown. 


\section{The Sol-Gel Transition \& Volumetric Contraction}

Rheology is commonly used to study the behaviour of phase transitions in polymeric systems [4]. The formation of the network during vulcanization, in which the transition from a rubbery to a solid state takes place, is characterized by the presence of permanent cross-links and by a sol-gel transition with the formation of a critical gel [5-6]. Critical gel shows a relaxation modulus, $\mathrm{G}(\mathrm{t})$ described by a power law, as follows:

$$
G(t)=S . t^{-n}
$$

where parameters $S$ and $n$ represent the rigidity and the critical relaxation exponent of the gel. While it is difficult to measure the $\mathrm{G}(\mathrm{t})$ modulus from step shear strain (stress-relaxation) tests, it is much easier to obtain it from simple frequency sweep tests. Applying the Laplace transform [7] of the function describing G(t), we can immediately obtain the complex modulus, $G^{*}$, as follows:

$$
G^{*}=s L(G(s))=S . \Gamma(1-n) \cdot s^{n}
$$

where $\mathrm{s}=\hat{\imath} \omega$ and $\hat{l}$ is the imaginary unit and $\omega$ the frequency. Noticing that $\mathrm{G}^{*}=\mathrm{G}^{\prime}+\hat{\imath} \mathrm{G}^{\prime \prime}$ the equation 3 is obtained:

$$
G^{*}=S \cdot \Gamma(1-n) \cdot \omega^{n} \cdot\left[\sin \left(\frac{n \pi}{2}\right)+\hat{\imath} \cos \left(\frac{n \pi}{2}\right)\right]
$$

\section{Experimental}

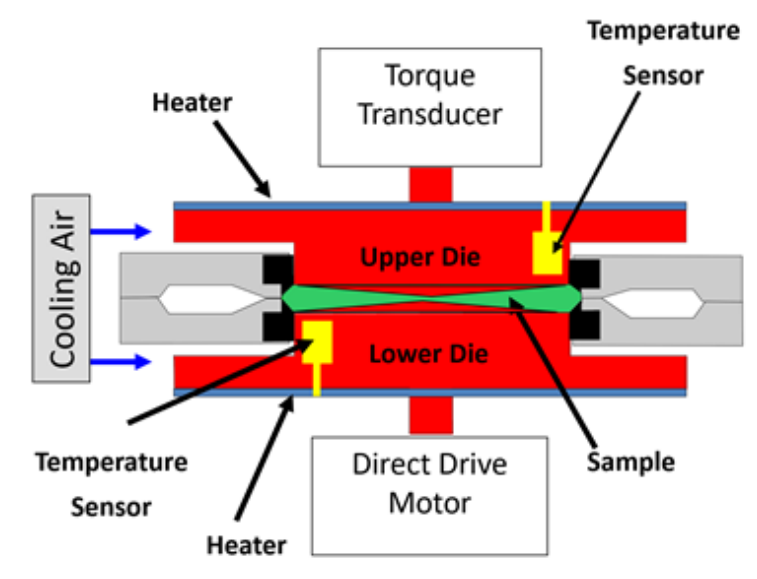

Figure 2: Measuring principle and features of the test die cavity.

In this study we investigated three different compounds named $\mathrm{C} 1 \mathrm{C} 2$ and $\mathrm{C} 3 . \mathrm{C} 1$ and $\mathrm{C} 2$ have the same vulcanizing system, based on dicumyl peroxide (DCP) at $1.3 \mathrm{phr}$ (taken as pure), without the addition of fillers. C1 is high cis polyisoprene (IR0310 Kraton) and C2 is NBR nitrile rubber (N3345). C3 is a typical tread rubber compound recipe for truck tire application, with NR, BR and e-SBR as given in Table 1. The elastic modulus $\mathrm{G}^{\prime}$ (MPa) was measured during isothermal vulcanization at 3 different temperatures, $150^{\circ} \mathrm{C}, 160^{\circ} \mathrm{C}$, and $170^{\circ} \mathrm{C}$, at a frequency of $1 \mathrm{~Hz}$ at $1 \%$ of deformation. Simultaneously the volumetric shrinkage of the compound under isothermal vulcanization conditions. The studies were made using a Premier ${ }^{\mathrm{TM}}$ RPA Plus analyser, commercialized by Alpha Technologies (company of the Roper Technologies group, Hudson, OH, USA). The resulting torque is measured and through the appropriate built-in data treatment, split into real and imaginary components in order to yield dynamic viscoelastic data, such as G' and G". The testing part consists in a biconical test chamber with grooved dies to avoid slippage. The cavity is closed through the action of a ram [8-9]. The torque measuring system is attached to the upper die and a direct drive motor move the lower die sinusoidally over a wide range of strains and frequencies as shown in Figure 2. The critical gel point, that is the time at which the sol-gel transition takes place at a given temperature, has been determined by carrying out a continuous sequence of frequency sweep tests (in the range between 1 and $30 \mathrm{~Hz}$ ) at a given curing temperature.

Table 1: Recipe of tread-like compound.

\begin{tabular}{|c|c|}
\hline Ingredient & PHR \\
\hline NR & 30 \\
\hline BR & 20 \\
\hline SBR1723 & 27.5 \\
\hline SBR1500 & 30 \\
\hline ZnO & 3 \\
\hline Stearic acid & 2 \\
\hline S & 1.5 \\
\hline CBS & 1.5 \\
\hline
\end{tabular}




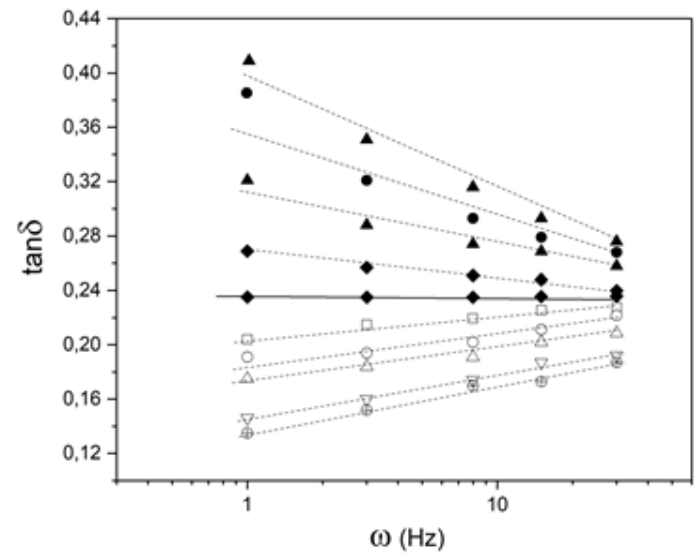

Figure 3: Trend in tan $\delta$ as a function of frequency during the curing of the compound $\mathrm{C} 1$ at the temperature of $150^{\circ} \mathrm{C}$. The datasets from top (filled triangles) to bottom (open circles) correspond to the following curing times: $0,100,150,200,250$, and, finally, 500s. The horizontal line corresponds to the formation of the critical gel at 250 s, where tan $\delta$ is independent of the frequency.

Figure 3 shows the results of these frequency sweep measurement obtained for C1 (IR compound) during isothermal vulcanization at $150^{\circ} \mathrm{C}$. Data shows that at $250 \mathrm{~s}$, the formation of the critical gel is observed: at the critical gel point $\tan \delta$ is no frequency independent as given in eq. 3. As shown inf Figure 1 the time in which the sol-gel transition takes place (tc, time in which critical gel formation is observed), it is characterized by a degree of vulcanization of $0.25-0.30$, regardless of the temperature at which the curing reaction occurs. The formation of the critical gel can therefore be related to the development of a crosslinked structure during vulcanization and its dependence on the curing temperature. Figure 3 shows the dependence of the critical gel time on the reciprocal of the vulcanization temperature for all compounds analysed. As expected, the formation of the critical gel occurs faster at higher temperatures, where the rate of vulcanization is faster. The dependence between the critical gel time and the vulcanization temperature follows the Arrhenius' equation as shown by the linear behaviour of $\log t_{c} v s .1 / T_{\text {curing }}$ in Figure 4. The calculated activation energy values are in excellent agreement with the experimental data available in the literature [5-6].

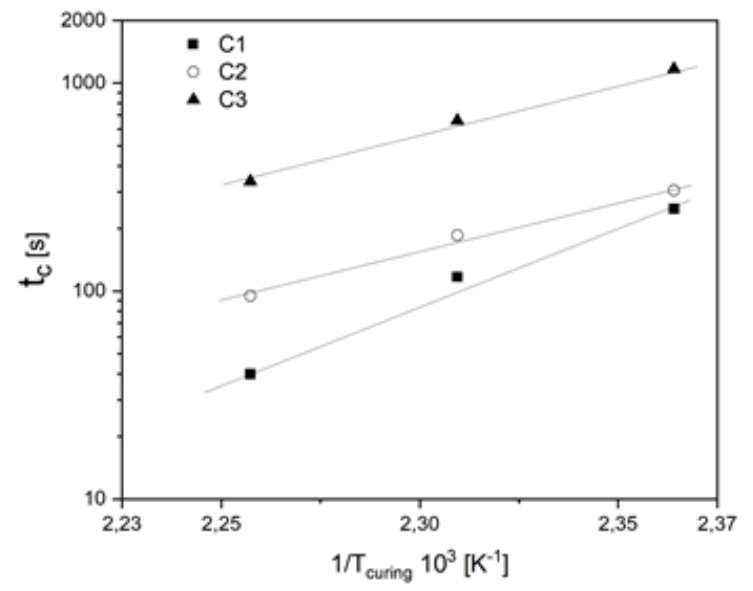

Figure 4: Critical gel formation time at various temperatures for the IR, NBR and C3 compound. The activation energy is respectively 17 and 11 and $12 \mathrm{Kcal} /(\mathrm{K} . \mathrm{mol})$.

The time to reach the sol-gel transition is faster for the C1 (IR) than for the nitrile compound (C2), while it becomes practically equal at approximately $135^{\circ} \mathrm{C}$, which is the temperature at which the DCP reaction rate becomes very slow. For the sulphur cured compound $\mathrm{C} 3$, the critical gel time is significantly longer than
$\mathrm{C} 1$ and $\mathrm{C} 2$ at the same temperature. In other words, the same $\mathrm{t}_{\mathrm{c}}$ has been reached for $\mathrm{C} 3$ at a temperature $20^{\circ} \mathrm{C}$ higher than the peroxide cured compounds. Figure 5 , shows the relaxation exponent vs. critical gel stiffness as a function of temperature. It is interesting to note that the stiffness of the critical gel slightly 
depends on temperature, and is characterized by particularly low values of $n$, especially at high temperatures (in the order of 0.10 ). These results suggest that the critical gel structure is qualitatively similar, independently of the elastomers and of the curing system and tend to be stiffer when formed in a curing reaction at high temperature, showing a quite limited time dependent relaxation modulus $G(\mathrm{t})$.

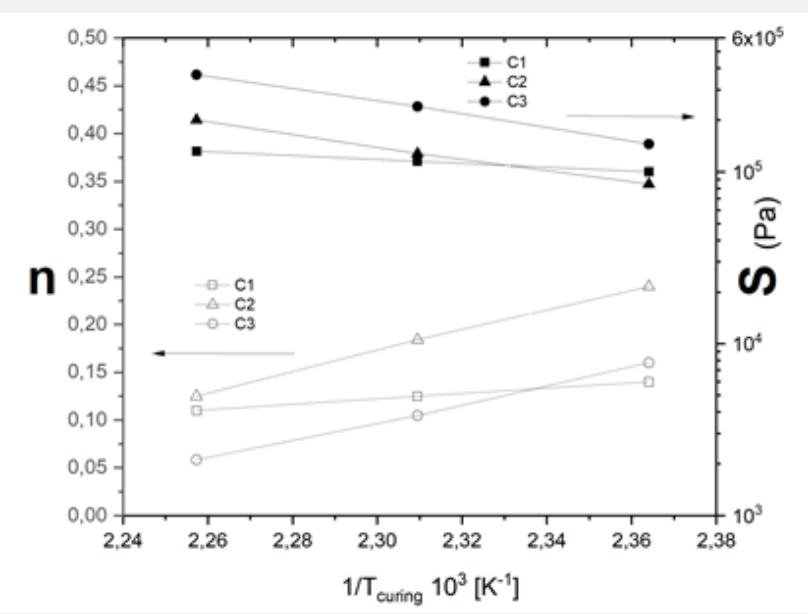

Figure 5: Relaxation exponent (non-filled symbols) and stiffness parameter S (filled symbols), of the critical gel for C1, C2 and C3 compound as a function of the isothermal curing temperature.

\section{Results and Conclusion}

The formation of the network during vulcanization, in which the transition from a rubbery to a solid state takes place, is characterized by a sol-gel transition with the formation of a critical gel. Frequency sweep test has been used to determine the time require to form the critical gel during vulcanization and has been found to takes place at a degree of vulcanization of 0.25-0.30, regardless of the temperature at which the curing reaction occurs. In this paper, it has been also shown experimentally that critical gel time follows the Arrhenius' equation and the stiffness of the critical gel slightly depends on temperature, and is characterized by particularly low values of $n$, especially at high temperatures (in the order of 0.10 ). These results suggest that the critical gel structure is qualitatively similar, independently of the elastomers and of the curatives.

\section{References}

1. Gent AN (2012) Engineering with rubber, Hanser-Verlag

2. Nichetti D (2003) J of Polymer Eng 23(6).
3. Cossar S, Nichetti D, Grizzuti N (2004) Rheological study of the phase transition in thermoplastic polyurethanes. Critical gel behavior and microstructure development. J Rheol 48(3).

4. Makio M (2003) Measurements study of vulcanization and degradation chemistry in natural rubber by solid-state $13 \mathrm{C}$ NMR and physical property. Rubber Chem Tech 76(5).

5. Winter HH, Chambon F (1986) J Rheol 30: 367.

6. Chambon F, Winter HH (1987) Linear viscoelasticity at the gel point of a crosslinking PDMS with imbalanced stoichiometry. J Rheol 31(8): 683.

7. Cho KS (2016) Viscoelasticity of Polymers, Springer.

8. Leblanc JL, Mongruel A (2001) Rubber Plast Technol 17: 162

9. Dick JS, Pawlowski H (1986) Applications of the rubber process analyzer in characterizing the effects of silica on uncured and cured compound properties. Rubb Div Mtg Montreal, Canada, Paper 34

10. De Rosa ME, Winter HH (1994) The effect of entanglements on the rheological behavior of polybutadiene critical gels. Rheo Acta 33(3).

11. Franck A, Hafner K, Kern WF (1962) The activation energy of vulcanization. Rubber Chem Tech 35(1): 76-91. 
(CC) This work is licensed under Creative

BY DOI: 10.19080/AJOP.2021.05.555655

\section{Your next submission with Juniper Publishers} will reach you the below assets

- Quality Editorial service

- Swift Peer Review

- Reprints availability

- E-prints Service

- Manuscript Podcast for convenient understanding

- Global attainment for your research

- Manuscript accessibility in different formats

( Pdf, E-pub, Full Text, Audio)

- Unceasing customer service

Track the below URL for one-step submission https://juniperpublishers.com/online-submission.php 